IJMS 27(2), 77-96 (2020)

How to cite this article:

Ibrahim, N. A., Kura, K. M., Dasuki, S. I., \& Abubakar Alkali, A. M. (2020). Problematic Internet use and health outcomes: Does trait self-control matter? International Journal of Management Studies, 27(2) July, 77-96. https:// doi.org/10.32890/ijms.27.2.2020.10569

\title{
PROBLEMATIC INTERNET USE AND HEALTH OUTCOMES: DOES TRAIT SELF-CONTROL MATTER?
}

\author{
NAJAFI AUWAL IBRAHIM \\ Department of Business Administration and Entrepreneurship \\ Bayero University, Kano, Nigeria \\ KABIRU MAITAMA KURA \\ UTB School of Business, Universiti Teknologi Brunei \\ Brunei Darussalam \\ SALIHU IBRAHIM DASUKI \\ University of Sheffield Information School, United Kingdom \\ ABUBAKAR MOHAMMED ALKALI \\ General Electric, South Africa \\ ${ }^{*}$ Corresponding author: naibrahim.bus@buk.edu.ng
}

\begin{abstract}
Problematic internet use is prevalent among university students, and it has been associated with increased adverse health outcomes. The results of existing research are mixed regarding the effects of problematic internet use on health outcomes. To resolve this ambiguity, we drew upon the self-control theory and person-situation interaction model to propose trait self-control as a moderator in the relationship between problematic internet use and adverse health outcomes. The study participants comprised 273 students from both public and private universities in Nigeria. Results reveal that problematic internet use is a significant predictor of adverse health outcomes. However,
\end{abstract}


we find no evidence to support our postulated Hypothesis that trait selfcontrol moderates the effects of problematic internet use on adverse health outcomes. Implications, limitations, and potential for future research are highlighted.

Keywords: Problematic Internet use, health outcomes, self-control.

Received: 27/6/2020 Revised: 20/8/2020 Accepted: 24/8/2020 Published: 11/10/2020

\section{Introduction}

Undoubtedly, the value of the Internet cannot be overestimated because it is being used in almost every field of human endeavour, including, teaching and learning, entertainment, business transactions, and communications (Akter \& Wamba, 2016; Law, Leung, \& Buhalis, 2009; Rolando, Salvador, \& Luz, 2013; Sachdeva \& Verma, 2015). Although extant literature provides evidence of the added value of the Internet, problematic Internet use (PIU) is a prevalent and severe health issue (Hassan, Alam, Wahab, \& Hawlader, 2020; Yang, Sato, Yamawaki, \& Miyata, 2013). PIU refers to "an inability to control one's use of the Internet, which leads to negative consequences in daily life" (Spada, 2014, p. 3). Evidence from a meta-analysis study by Zhang, Lim, Lee, and Ho (2018) has shown that the prevalence of PIU among university students is roughly 30.1 percent. In Saudi Arabia, the prevalence of PIU among University students is estimated to have reached 26.5 percent (Abdel-Salam, Alrowaili, Albedaiwi, Alessa, \& Alfayyadh, 2019). In Nigeria, it has been reported that problematic use of smartphones and the Internet is a growing problem among adolescents (Onyeji, 2019). In a very recent study in Nigeria by Omoyemiju and Popoola (2020), PIU is more prevalent among undergraduate students between 20 and 30 years of age.

Prior studies (e.g., Caplan, 2003; Heim, 2012; Niemz, Griffiths, \& Banyard, 2005; Ponnusamy, Iranmanesh, Foroughi, \& Hyun, 2020; Yan, Li, \& Sui, 2014) have shown that PIU is associated with a wide range of social and psychological problems, including social isolation and high level of stress, low self-esteem, depression and anxiety, poor academic performance and schizophrenia. Research has also indicated that uncontrolled Internet use is positively related to increased psychological distress, anxiety disorder, as well as depression symptoms among undergraduate students in Nigeria 
(Akpunne \& Akinnawo, 2018). Given the prevalence and significant consequences of PIU, knowledge about when and how it is related to adverse health outcomes could have important practical implications.

Prior research on the relationship between PIU and adverse health outcomes has yielded contradictory and inconsistent findings (An et al., 2014; Bener et al., 2011; Canan et al., 2013; Choi et al., 2009; Domoff, Borgen, Foley, \& Maffett, 2019; Gámez-Guadix, 2014; Ostovar et al., 2016; Shadzi, Salehi, \& Vardanjani, 2020; van Deursen, Bolle, Hegner, \& Kommers, 2015). To address these inconsistencies, we used a moderator variable in the relationship between PIU and adverse health outcomes. Introduction of the moderator variable in this study is consistent with Baron and Kenny (1986). They explicitly highlighted the need to introduce a moderator variable, "when there is an unexpectedly weak or inconsistent relationship between a predictor and a criterion variable" (p. 1178). Hence, this study proposes trait self-control as a moderator in the relationship between PIU and adverse health outcomes.

As defined by Tangney, Baumeister, and Boone (2004), trait self-control refers to, "the ability to override or change one's inner responses, as well as to interrupt undesired behavioural tendencies and refrain from acting on them" (p. 275). Consistent with the person-situation interaction model (Bowers, 1973; Endler, 1975; Howard, 1979), we postulate that trait self-control positively moderates the relationship between PIU and adverse health outcomes, because individuals high in self-control are more likely to resist temptation and often think twice before they act, explicitly engaging in PIU, in this study (Błachnio \& Przepiorka, 2016; Fennis, Janssen, \& Vohs, 2009; Tangney et al., 2004). Therefore, the main research question of this study is when and how does trait self-control moderate the relationship between PIU and adverse health outcomes? Towards this end, the primary objective of this study is to investigate the moderating effect of trait self-control on the relationship between PIU and adverse health outcomes.

\section{Literature Review}

\section{Problematic Internet Use and Negative Health Outcomes}

PIU has been receiving considerable attention of late, which has led to its inclusion as one of the emerging disorders; because of how it is 
affecting both health and institutional performance (Machimbarrena et al., 2018; Moreno, Eickhoff, Zhao, \& Suris, 2019; Recupero, 2008). The evidence on the association between PIU and detrimental health-related outcomes is equivocal as some studies have found a positive relationship. In contrast, others have established an inverse relationship between the two variables. For example, in a crosssectional study involving 13,723 secondary school students from four large cities in China, An et al. (2014) found that PIU is significantly associated with increased physical and psychological symptoms. They concluded that PIU is a significant public health issue that requires immediate attention (An et al., 2014). There is also strong evidence that PIU is associated with excess weight and impaired vision (Bener et al., 2011; Wei et al., 2017). Furthermore, Cabral et al. (2016) and Ostovar et al. (2016) found that PIU causes loneliness and depression symptoms. Similarly, Moreno, Jelenchick, and Breland (2015) showed that PIU has adverse life consequences from both physical and emotional contexts. Numerous other studies have further confirmed the positive relationship between PIU and adverse healthrelated outcomes (Canan et al., 2013; Choi et al., 2009; Gámez-Guadix, 2014; van Deursen et al., 2015). In a systematic review of empirical studies, Domoff et al. (2019) reported mixed results, as they found that problematic social networking use is positively associated with increased sleep disruptions. However, they were not able to conclude due to conflicting findings regarding the effect of problematic mobile use on obesity risk, sleep duration and physical activity. In a related study, Shadzi et al. (2020) found that PIU may not result in adverse health-related outcomes, such as sleep disturbances and mental health issues. Therefore, this research proposes that:

$\mathrm{H}_{1}$ : Problematic internet use positively influences adverse health outcomes.

\section{Trait Self-Control as a Boundary Condition between Problematic Internet Use and Adverse Health Outcomes}

Given this recent finding by Shadzi et al. (2020), it is reasonable to speculate that the relationship between PIU and unfavourable healthrelated outcomes could vary across individuals. Hence, we propose that trait self-control has the potential to moderate the relationship between PIU and unfavourable health outcomes positively. To the best of our knowledge, no research has yet considered the moderating 
role of trait self-control in the relationship between PIU and adverse health-related consequences. Two reasons justify the significance of incorporating trait self-control as a moderator in this study. First, individuals high in self-control have higher tendency to resist temptation and often think twice before they act; hence, they are less likely to engage in PIU (Fennis et al., 2009; Tangney et al., 2004). Second, since prior research has indicated that individuals with lower self-control are more likely to engage in PIU, we argue that lower self-control would heighten PIU, consequently increasing adverse health outcomes (Błachnio \& Przepiorka, 2016; Jiang \& Zhao, 2016; Li et al., 2013; Mei, Yau, Chai, Guo, \& Potenza, 2016). For these reasons, we expect trait self-control to serve as a boundary condition between PIU and adverse health outcomes. Given the above, the following is hypothesized:

$\mathrm{H}_{2}$ : Trait self-control moderates the relationship between problematic internet use and adverse health outcomes.

\section{Methodology}

\section{Participants and Procedure}

A total of 273 undergraduate students enrolled in the Organizational Behaviour course at large public and private universities in Nigeria participated in this study. The survey was administered to the students in the lecture theatre during a regular class period. However, before distributing the survey packets, all participants were informed that participation in the study is voluntary, and it would enable them to gain some experience in psychological research. All participants were also assured of confidentiality and were told that the study aims to examine when and how PIU is related to adverse health outcomes. Of these respondents, 71 percent are male; they average 24.86 years (SD $=4.12$ ) in age.

Regarding their ethnic background, 67 percent are Hausa, Yoruba, 12 percent and 21 percent are other ethnic groups. To determine the possibility and degree of non-response bias and common method variance in the present study, we conducted an independent samples t-test and Harman's single-factor test (Armstrong \& Overton, 1977; Podsakoff, MacKenzie, Lee, \& Podsakoff, 2003). Harman's single factor 
test showed that variance explained for first factor in the analysis was 35 percent. We, therefore, concluded that common method variance is not a source of concern in this study.

\section{Measures}

Problematic Internet Use (PIU). To measure PIU, we used eight items from the Scale of Problematic Internet Use developed by da Fonsêca, Couto, do Vale Melo, Machado, and Filho (2018). Respondents rated the degree to which they agree or disagree with each of the eight items using a seven-point Likert-type scale ( 1 = "Strongly disagree"; 7 = "Strongly agree"). Sample items include, "On some occasions, I have lost hours of sleep to use the Internet"; "There are times when I'm in a bad mood because I cannot connect"; and "It is important to me to connect daily to Facebook, Twitter, Instagram, etc.". The Cronbach's alpha reported in the Scale of Problematic Internet is 0.84.

Trait Self-Control. We measured trait self-control using the 13item Brief Self-Control Scale developed by Tangney et al. (2004). Respondents rated each item using a seven-point Likert-type scale ( 1 = "Strongly disagree"; 7 = "Strongly agree"). Sample items include, "I am good at resisting temptation"; "I have a hard time breaking bad habits"; and "I never allow myself to lose control". The 13-item Brief Self-Control Scale has an average Cronbach's alpha of 0.84 .

Negative Health Outcomes. The 12-Item General Health Questionnaire (GHQ-12; Goldberg \& Williams, 1988) was utilized to measure various aspects of adverse health outcomes. Respondents rated the degree to which they agree or disagree with each of the 12 items using a seven-point Likert-type scale ( 1 = "Strongly disagree"; 7 = "Strongly agree"). Sample items include, "Loss of sleep over worry"; "Felt constantly under strain"; and "Feeling unhappy and depressed". The Cronbach's alpha reported in the Scale of Problematic Internet is 0.78 .

\section{Data Analysis}

Following the two-step process suggested by Henseler, Ringle, and Sinkovics (2009), partial least squares (PLS) path modeling technique using SmartPLS 3.3.1 (Ringle, Wende, \& Becker, 2015) was used to test our proposed measurement model before evaluating the structural 
model. PLS path modeling is suitable to test a model with several constructs and indicators simultaneously. The rationale for choosing PLS path modeling are as follows: First, this study is directed toward predicting the dependent variable (Hair, Hult, Ringle, \& Sarstedt, 2017); and second, PLS path modelling is considered as "the most fully developed and general system" (McDonald, 1996, p. 204) of the variance-based structural equation modeling techniques.

\section{Results}

\section{Outer Model Assessment}

To start, the outer model was examined to evaluate the internal consistency and convergent validity using item loadings, t-statistics, Average variance extracted (AVE), Cronbach's alpha $(\alpha)$ and composite reliability (CR). As shown in Table 1, the scale items, standardized factor loadings and their respective $t$-values are significant. Following Hair et al. (2017), the Cronbach's Alpha , CR, and AVE values exceed the threshold values of $0.70,0.70$ and 0.50 , respectively (see Table 1 ).

Table 1

Results of Measurement Model

\begin{tabular}{lcccc}
\hline Constructs and indicators & $\begin{array}{c}\text { Standardized } \\
\text { loadings }\end{array}$ & $\begin{array}{c}\text { Cronbach's } \\
\text { alpha }\end{array}$ & CR & AVE \\
\hline Problematic Internet Use & & 0.90 & 0.92 & 0.58 \\
PIU01 & 0.77 & & & \\
PIU02 & 0.82 & & & \\
PIU03 & 0.75 & & \\
PIU04 & 0.70 & & \\
PIU05 & 0.77 & & \\
PIU06 & 0.85 & & \\
PIU07 & 0.75 & & \\
PIU08 & 0.67 & & \\
\end{tabular}

(continued) 
IJMS 27(2), 77-96 (2020)

\begin{tabular}{lcccc}
\hline Constructs and indicators & $\begin{array}{c}\text { Standardized } \\
\text { loadings }\end{array}$ & $\begin{array}{c}\text { Cronbach's } \\
\text { alpha }\end{array}$ & CR & AVE \\
\hline Trait Self-Control & 0.71 & 0.93 & 0.94 & 0.66 \\
TSC03 & 0.77 & & & \\
TSC06 & 0.74 & & & \\
TSC07 & 0.74 & & & \\
TSC08 & 0.87 & & & \\
TSC09 & 0.83 & & & \\
TSC10 & 0.90 & & & \\
TSC11 & 0.91 & & & \\
TSC12 & & & & \\
Negative Health & & 0.90 & 0.92 & 0.55 \\
Outcomes & & & \\
NHO04 & 0.72 & & \\
NHO05 & 0.83 & & \\
NHO06 & 0.69 & & \\
NHO07 & 0.74 & & \\
NHO08 & 0.71 & & \\
NHO09 & 0.81 & & \\
NHO10 & 0.78 & & \\
NHO11 & 0.73 & & \\
NH012 & 0.70 & & \\
\hline
\end{tabular}

Note: $\mathrm{CR}=$ Composite Reliability; $\mathrm{AVE}=$ Average Variance Extracted

We then examined the discriminant validity of the study constructs using the Fornell and Larcker (1981) approach, where for each construct, the square root of AVE values (diagonal values) is higher than its correlation coefficients with other constructs (See Table 2). Based on this result, we can infer that internal consistency, and convergent and discriminant validity is proven. We used the Heterotrait-Monotrait (HTMT) Ratio Criterion (Table 2) to confirm the discriminant validity further. According to Henseler, Ringle, and Sarstedt (2015), if the value of the HTMT Ratio is equivalent to or less than the value of 0.85 , there is proof of discriminant validity. All HTMT values are below 0.85, as shown in Table 2. 


\section{Structural Model Evaluation}

To test direct and moderating effects in the structural model, we used the standardized beta values, $t$-values, Bootstrapped Confidence Intervals, $R^{2}$ and effect size $\left(f^{2}\right)$ values of the endogenous variables (see Figure 1). We also employed a bootstrapping technique with a resample of $\mathrm{N}=5,000$. Table 3 shows that PIU has a significant and positive effect on adverse health outcomes, as the confidence interval does not contain zero at the 2.5 percent level $(\beta=10.23, \mathrm{CI}=[0.50$; 0.66]). This confirms Hypothesis 1 . On the contrary, it appears that trait self-control does not moderate the association between PIU and negative health outcomes $(\beta=1.42, \mathrm{CI}=[-.11 ; 0.16])$. Hence, Hypothesis 2 is not supported.

Table 2

Results of Discriminant Validity

\begin{tabular}{lcccccc}
\hline & \multicolumn{3}{c}{$\begin{array}{c}\text { Fornell-Larcker } \\
\text { Criterion }\end{array}$} & \multicolumn{3}{c}{$\begin{array}{c}\text { Heterotrait-Monotrait } \\
\text { Ratio }\end{array}$} \\
& 1 & 2 & 3 & 1 & 2 & 3 \\
\hline $\begin{array}{l}\text { 1. Problemt constructs } \\
\quad \text { Use }\end{array}$ & 0.76 & & & & & \\
$\begin{array}{l}\text { 2. Trait Self-Control } \\
\begin{array}{l}\text { 3. Negative Health } \\
\quad\end{array}\end{array}$ & -0.23 & 0.81 & & 0.30 & \\
$\quad$ Outcomes & 0.52 & 0.18 & 0.74 & 0.55 & 0.20 \\
\hline
\end{tabular}

Note: Composite Reliability $(\mathrm{CR})=$ Numbers in italics represent the square root of the Average Variance Extracted (AVE)

Following Hair, Ringle, and Sarstedt (2011), the $R^{2}$ value of 0.37 $(37 \%)$ is higher than 0.26 , indicating a significant contribution of the latent exogenous variable to explain the endogenous variable (see Table 3). PIU accounts for 37 percent of the variability in adverse health outcomes. Furthermore, in a structural model, Hair et al. (2017) suggested documenting $f^{2}$ for each predictor construct (s) on the endogenous variable (s). Table 3 shows that both PIU and trait self-control have a medium effect on adverse health outcomes with $f^{2}$ values of 0.19 and 0.15 , respectively (Cohen, 1988). 
IJMS 27(2), 77-96 (2020)

Table 3

Results of Structural Model

$97.5 \%$

Hypotheses Relationship Beta SE $t$-value $\begin{gathered}\text { Bootstrapped } \\ \text { Confidence } \\ \text { Intervals }\end{gathered}$ Findings

\begin{tabular}{lllllll}
\hline $\mathrm{H}_{1}$ & PIU $->$ NHO & 0.58 & 0.06 & 10.23 & {$[0.50 ; 0.66]$} & Supported \\
& PIU x TSC -> & & & & & $\begin{array}{l}\text { Not } \\
\mathrm{H}_{2}\end{array}$ \\
NHO & 0.11 & 0.08 & 1.42 & {$[-0.11 ; 0.16]$} & Supported
\end{tabular}

$R^{2}=0.37$

$Q^{2}=0.53$

$f^{2}:(\mathrm{PIU}->\mathrm{NHO}=0.19 ; \mathrm{TSC}->\mathrm{NHO}=0.15)$

Note: PIU = Problematic Internet Use; TSC = Trait Self-Control; NHO = Negative Health Outcomes; SE = Standard Error

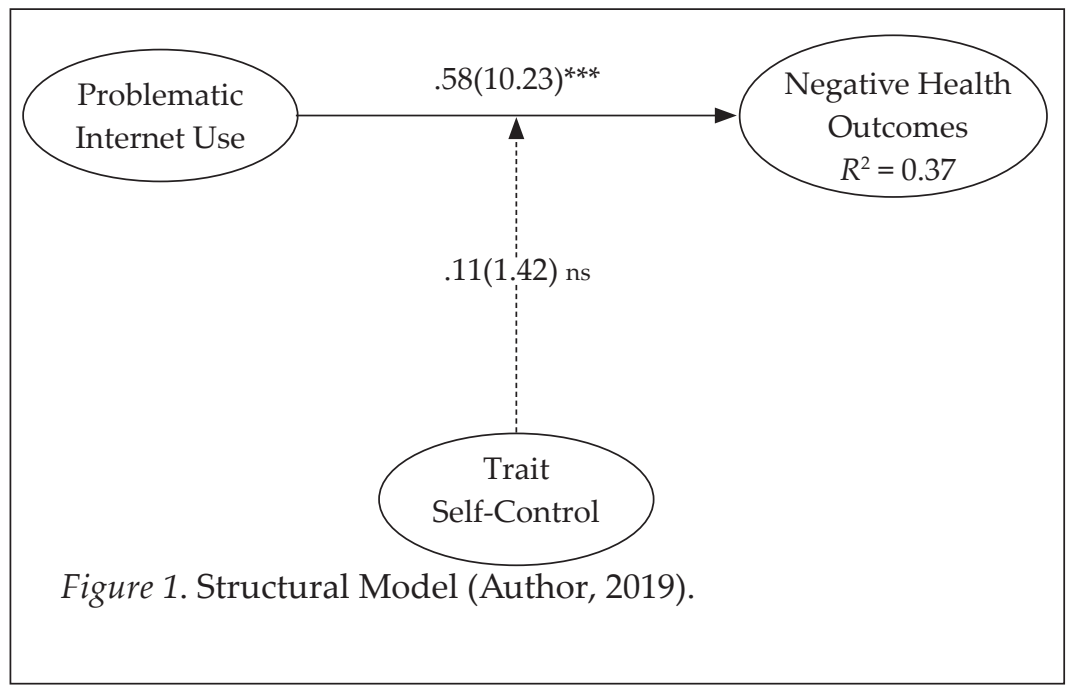

Note: values in parentheses represent $t$-values, and those outside parentheses are the path coefficients; ns = not significant 


\section{Discussion}

Drawing on the self-control theory (Gottfredson \& Hirschi, 1990) and person-situation interaction model (Bowers, 1973; Endler, 1975; Howard, 1979), this study investigated trait self-control as a moderator in the relationship between PIU and adverse health outcomes. First, concerning our first hypothesis, we find that PIU has a positive and significant impact on adverse health outcomes. This finding is not surprising because it confirms prior research (e.g., An et al., 2014; Bener et al., 2011; Canan et al., 2013; Choi et al., 2009; Gámez-Guadix, 2014; van Deursen et al., 2015; Wei et al., 2017), that PIU is positively associated with increased adverse health outcomes, including excess weight, impaired vision, depression symptoms, and increased sleep disruptions, among others.

Second, we find no evidence to support our second Hypothesis that trait self-control moderates the effects of PIU on adverse health outcomes. This is an interesting finding as it is inconsistent with the self-control theory (Gottfredson \& Hirschi, 1990), which postulates that low self-control is an essential factor underlying PIU. The insignificant moderating effect is also inconsistent with the personsituation interaction model (Bowers, 1973; Endler, 1975; Howard, 1979), which suggests that "situations are as much a function of the person as the person's behaviour is a function of the situation" ( $p$. 327).

There are several reasons for the insignificant result of the moderating variable. One reason can be attributed to the demographic characteristics of our study participants. As reported above, our participants comprised 71 percent male. Research has consistently shown that males are more likely to engage in PIU than females (Dufour et al., 2016; Su, Han, Jin, Yan, \& Potenza, 2019). Further, extant research has shown that males tend to have lower level self-control, compared to females, and this makes it easy for them to engage in PIU (Shekarkhar \& Gibson, 2011). Thus, it is plausible that having a higher proportion of male participants in this study, coupled with their lower self-control, yielded the insignificant moderating effect. Another likely reason for the insignificant result of the moderating effect may be due to insufficient evidence in our dataset. As contended 
by Littler (2020), "larger sample sizes give more reliable results with greater precision and power", hence, justifying the insignificant moderating effect.

\section{Theoretical and Managerial Implications}

From the theoretical perspective, the present study adds to the knowledge on the self-control theory (Gottfredson \& Hirschi, 1990) and person-situation interaction model (Bowers, 1973; Endler, 1975; Howard, 1979), in two ways. First, even though the self-control theory postulates PIU as a critical factor underlying adverse health outcomes, to our knowledge, no empirical work to date has added to this theory by incorporating trait self-control as a boundary condition between PIU and adverse health outcomes. Hence, our study contributes by proposing and testing a theoretical model incorporating trait selfcontrol as a moderator in the relationship between PIU and adverse health outcomes.

Besides its theoretical implications, the present study has important practical consequences for PIU prevention and intervention strategies. Specifically, our findings suggest the importance of training to strengthen students' self-control against negative consequences associated with PIU. Thus, practical self-control training should be given to students by teachers and school administrators to help them achieve positive outcomes. This is because prior research has established that students who receive self-control training are more likely to achieve positive outcomes than those who do not receive such training (Beneke \& Harris, 1972). In addition to providing self-control training to students, prevention strategies should target parents and guardians directly. In this case, "education and the heightening of parental media literacy are other important and direct preventive efforts" (Lee, Kim, \& Lee, 2019, p. 306). This can be achieved by providing media literacy training to parents and guardians directly to ensure that healthy Internet behaviour among their children (Lee et al., 2019).

\section{Limitations and Future Research Directions}

Like other research, this work suffers from several limitations. The study design is one of the critical limitations of this work. In particular, 
the use of cross-sectional research design in this study does not allow us to make unconditional conclusions about causal relationships. It is hoped that future research can address this limitation by designing and implementing longitudinal research or use cross-lagged models to test the causal relationships between the latent variables. Another limitation of the current study is related to data collection strategy (Hetland, Hetland, Bakker, \& Demerouti, 2018; Mayer, Thau, Workman, Dijke, \& Cremer, 2012).

Although the result of Harman's single factor test shows that the first factor was less than $50 \%$, we encourage future researchers to replicate the present study by collecting data at different times, using various sources to rule out the possibility of variance that is attributable to the measurement method (Podsakoff et al., 2003). Finally, including only undergraduate students from two public and private universities in Nigeria might affect the generalizability of our findings to other universities.

\section{Conclusion}

This study enhances our understanding of the unique conditions under which PIU is related to adverse health outcomes. However, contrary to our expectations, we find no evidence to support our postulation that trait self-control is a pre-existing variable that moderates the relationship between PIU and adverse health outcomes. Although we find no evidence to support our moderating effect, we cannot rule out the possibility that the non-significant result is due to insufficient evidence in our dataset. Hence, collecting data from a larger sample could benefit future research. Taken together, the present study has provided additional evidence to the growing body of knowledge concerning the moderating role of trait self-control on the relationship between PIU and adverse health outcomes. In addition to the theoretical contributions, the results from this study provide some important practical implications to policy makers.

\section{Acknowledgement}

This research received no specific grant from any funding agency. 
IJMS 27(2), 77-96 (2020)

\section{References}

Abdel-Salam, D. M., Alrowaili, H. I., Albedaiwi, H. K., Alessa, A. I., \& Alfayyadh, H. A. (2019). Prevalence of Internet addiction and its associated factors among female students at Jouf University, Saudi Arabia. Journal of the Egyptian Public Health Association, 94(1), 12. https://doi:10.1186/s42506-019-0009-6

Akpunne, B. C., \& Akinnawo, O. E. (2018). Internet addiction, problematic smartphone use and psychological health of Nigerian University Undergraduates. International Neuropsychiatric Disease Journal, 12(3), 1-13. https://doi:10.9734/ indj/2018/v12i330093

Akter, S., \& Wamba, S. F. (2016). Big data analytics in E-commerce: A systematic review and agenda for future research. Electronic Markets, 26(2), 173-194. https://doi:10.1007/s12525-016-0219-0

An, J., Sun, Y., Wan, Y., Chen, J., Wang, X., \& Tao, F. (2014). Associations between problematic Internet use and adolescents' physical and psychological symptoms: Possible role of sleep quality. Journal of Addiction Medicine, 8(4), 282-287. https://doi:10.1097/ adm.0000000000000026

Armstrong, J. S., \& Overton, T. S. (1977). Estimating nonresponse bias in mail surveys. Journal of Marketing Research, 14(3), 396-402. https://doi:10.1177/002224377701400320

Baron, R. M., \& Kenny, D. A. (1986). The moderator-mediator variable distinction in social psychological research: Conceptual, strategic, and statistical considerations. Journal of personality and social psychology, 51(6), 1173-1182. https://doi:10.1037/00223514.51.6.1173

Beneke, W. M., \& Harris, M. B. (1972). Teaching self-control of study behavior. Behaviour Research and Therapy, 10(1), 35-41. https:// doi.org/10.1016/0005-7967(72)90005-8

Bener, A., Al-Mahdi, H. S., Ali, A. I., Al-Nufal, M., Vachhani, P. J., \& Tewfik, I. (2011). Obesity and low vision as a result of excessive Internet use and television viewing. International Journal of Food Sciences and Nutrition, 62(1), 60-62. https://doi:10.3109/0963748 6.2010 .495711

Błachnio, A., \& Przepiorka, A. (2016). Dysfunction of self-regulation and self-control in facebook addiction. Psychiatric Quarterly, 87(3), 493-500. https://doi:10.1007/s11126-015-9403-1 
Bowers, K. S. (1973). Situationism in psychology: An analysis and a critique. Psychological Review, 80(5), 307-336. https://doi:10.1037/ h0035592

Cabral, L., Duarte, J., Oliveira, A., Neves, L., Fonseca, M., Marques, S., \& Gonçalves, A. (2016). The impact of Internet addiction on the mental health of college students from the central area of Portugal. Atención Primaria, 48(Espec Cong 1), 253-258.

Canan, F., Yildirim, O., Ustunel, T. Y., Sinani, G., Ozturk, O., Gunes, C., \& Ataoglu, A. (2013). The relationship between Internet addiction and body mass index in turkish adolescents. European Psychiatry, 28, 1. https://doi:https://doi.org/10.1016/ S0924-9338(13)75792-4

Caplan, S. E. (2003). Preference for online social interaction: A theory of problematic internet use and psychosocial wellbeing. Communication Research, 30(6), 625-648. https:// doi:10.1177/009365020325 7842

Choi, K., Son, H., Park, M., Han, J., Kim, K., Lee, B., \& Gwak, H. (2009). Internet overuse and excessive daytime sleepiness in adolescents. Psychiatry and Clinical Neurosciences, 63(4), 455462. https://doi:10.1111/j.1440-1819.2009.01925.x

Cohen, J. (1988). Statistical power analysis for the behavioral sciences. Hillsdale, NJ: Lawrence Erlbaum Associates.

da Fonsêca, P. N., Couto, R. N., do Vale Melo, C. C., Machado, M. d. O. S., \& Filho, J. F. d. S. (2018). Scale of problematic internet use in university students: Evidence of validity and reliability. Ciencias Psicológicas, 12(2), 223-230. https://doi:10.22235/ cp.v12i2.1686

Domoff, S. E., Borgen, A. L., Foley, R. P., \& Maffett, A. (2019). Excessive use of mobile devices and children's physical health. Human Behavior and Emerging Technologies, 1(2), 169-175. https:// doi:10.1002/hbe2.145

Dufour, M., Brunelle, N., Tremblay, J., Leclerc, D., Cousineau, M.-M., Khazaal, Y., \& Berbiche, D. (2016). Gender difference in internet use and internet problems among quebec high school students. Canadian Journal of Psychiatry. Revue Canadienne de Psychiatrie, 61(10), 663-668. https://doi:10.1177/0706743716640755

Endler, N. S. (1975). The case for person-situation interactions. Canadian Psychological Review/Psychologie canadienne, 16(1), 1221. https://doi:10.1037/h0081784 
Fennis, B. M., Janssen, L., \& Vohs, K. D. (2009). Acts of benevolence: A limited-resource account of compliance with charitable requests. Journal of Consumer Research, 35(6), 906-924.

Fornell, C., \& Larcker, D. F. (1981). Evaluating Structural Equation Models with unobservable variables and measurement error. Journal of Marketing Research, 18, 39-50.

Gámez-Guadix, M. (2014). Depressive symptoms and problematic Internet use among adolescents: Analysis of the longitudinal relationships from the cognitive-behavioral model. Cyberpsychology, behavior and social networking, 17(11), 714-719. https://doi:10.1089/cyber.2014.0226

Goldberg, D., \& Williams, P. (1988). A user's guide to the General Health Questionnaire. Windsor, UK: NFER-Nelson.

Gottfredson, M. R., \& Hirschi, T. (1990). A general theory of crime: Stanford University Press.

Hair, J. F., Hult, G. T. M., Ringle, C. M., \& Sarstedt, M. (2017). A primer on partial least squares structural equation modeling (PLS-SEM). Thousand Oaks: Sage Publications.

Hair, J. F., Ringle, C. M., \& Sarstedt, M. (2011). PLS-SEM: Indeed a silver bullet. Journal of Marketing Theory and Practice, 18, 139152.

Hassan, T., Alam, M. M., Wahab, A., \& Hawlader, M. D. (2020). Prevalence and associated factors of internet addiction among young adults in Bangladesh. Journal of the Egyptian Public Health Association, 95(1), 1-8. https://doi:10.1186/s42506-019-0032-7

Heim, C. (2012). Very heavy computer and Internet usage as a risk factor for schizophrenia in intelligent young males. Australian E New Zealand Journal of Psychiatry, 46(8), 791-792. https:// doi:10.1177/0004867412442407

Henseler, J., Ringle, C. M., \& Sarstedt, M. (2015). A new criterion for assessing discriminant validity in variance-based structural equation modeling. Journal of the Academy of Marketing Science, 43(1), 115-135. https://doi:10.1007/s11747-014-0403-8

Henseler, J., Ringle, C. M., \& Sinkovics, R. R. (2009). The use of partial least squares path modeling in international marketing. In $\mathrm{R}$. R. Sinkovics \& P. N. Ghauri (Eds.), Advances in International Marketing (Vol. 20, pp. 277-320). Bingley: Emerald

Hetland, J., Hetland, H., Bakker, A. B., \& Demerouti, E. (2018). Daily transformational leadership and employee job crafting: The role of promotion focus. European Management Journal, 36(6), 746-756. https://doi.org/10.1016/j.emj.2018.01.002 
Howard, J. A. (1979). Person-situation interaction models. Personality and Social Psychology Bulletin, 5(2), 191-195. https:// doi:10.1177/014616727900500214

Jiang, Z., \& Zhao, X. (2016). Self-control and problematic mobile phone use in Chinese college students: The mediating role of mobile phone use patterns. BMC Psychiatry, 16(1), 416. https:// doi:10.1186/s12888-016-1131-z

Law, R., Leung, R., \& Buhalis, D. (2009). Information technology applications in hospitality and tourism: A review of publications from 2005 to 2007. Journal of Travel \& Tourism Marketing, 26(56), 599-623. https://doi:10.1080/10548400903163160

Lee, S.-Y., Kim, M. S., \& Lee, H. K. (2019). Prevention strategies and interventions for Internet use disorders due to addictive behaviors based on an integrative conceptual model. Current Addiction Reports, 6(3), 303-312. https://doi:10.1007/s40429-01900265-z

Li, D., Li, X., Wang, Y., Zhao, L., Bao, Z., \& Wen, F. (2013). School connectedness and problematic Internet use in adolescents: A moderated mediation model of deviant peer affiliation and self-control. Journal of Abnormal Child Psychology, 41(8), 12311242. https://doi:10.1007/s10802-013-9761-9

Littler, S. (2020). The importance and effect of sample size. Retrieved from https://select-statistics.co.uk/blog/importance-effectsample-size/

Mayer, D. M., Thau, S., Workman, K. M., Dijke, M. V., \& Cremer, D. D. (2012). Leader mistreatment, employee hostility, and deviant behaviors: Integrating self-uncertainty and thwarted needs perspectives on deviance. Organizational Behavior and Human Decision Processes, 117(1), 24-40. https://doi.org/10.1016/j. obhdp.2011.07.003

McDonald, R. P. (1996). Path Analysis with composite variables. Multivariate Behavioral Research, 31(2), 239-270. https:// doi:10.1207/s15327906mbr3102_5

Mei, S., Yau, Y. H. C., Chai, J., Guo, J., \& Potenza, M. N. (2016). Problematic Internet use, well-being, self-esteem and selfcontrol: Data from a high-school survey in China. Addictive Behaviors, 61, 74-79. https://doi:10.1016/j.addbeh.2016.05.009

Moreno, M. A., Jelenchick, L. A., \& Breland, D. J. (2015). Exploring depression and problematic Internet use among college females: A multisite study. Computers in Human Behavior, 49, 601-607. https://doi.org/10.1016/j.chb.2015.03.033 
Niemz, K., Griffiths, M., \& Banyard, P. (2005). Prevalence of pathological Internet use among university students and correlations with self-esteem, the general health questionnaire (GHQ), and disinhibition. CyberPsychology \& Behavior, 8(6), 562-570. https://doi:10.1089/cpb.2005.8.562

Omoyemiju, M. A., \& Popoola, B. I. (2020). Prevalence of Internet addiction among students of Obafemi Awolowo University, Ile-Ife, Nigeria. British Journal of Guidance \& Counselling, 1-11. https://doi:10.1080/03069885.2020.1729339

Onyeji, E. (2019, April 17). Addictive' use of smartphones, Internet worries Nigerian health officials. The Premium Times. Retrieved fromhttps://www.premiumtimesng.com/health/health news/325809-addictive-use-of-smartphones-internet-worriesnigerian-health-officials.html

Ostovar, S., Allahyar, N., Aminpoor, H., Moafian, F., Nor, M. B. M., \& Griffiths, M. D. (2016). Internet Addiction and its Psychosocial Risks (Depression, Anxiety, Stress and Loneliness) among Iranian Adolescents and Young Adults: A Structural Equation Model in a Cross-Sectional Study. International Journal of Mental Health and Addiction, 14(3), 257-267. https://doi:10.1007/s11469015-9628-0

Podsakoff, P. M., MacKenzie, S. B., Lee, J.-Y., \& Podsakoff, N. P. (2003). Common method biases in behavioral research: A critical review of the literature and recommended remedies. Journal of Applied Psychology, 88, 879-903.

Ponnusamy, S., Iranmanesh, M., Foroughi, B., \& Hyun, S. S. (2020). Drivers and outcomes of Instagram Addiction: Psychological well-being as moderator. Computers in Human Behavior, 107, 106294. https://doi.org/10.1016/j.chb.2020.106294

Ringle, C. M., Wende, S., \& Becker, J.-M. (2015). SmartPLS 3. Bönningstedt: SmartPLS. Retrieved from http://www.smartpls. com.

Rolando, L. G. R., Salvador, D. F., \& Luz, M. R. M. P. (2013). The use of Internet tools for teaching and learning by in-service biology teachers: A survey in Brazil. Teaching and Teacher Education, 34, 46-55. https://doi.org/10.1016/j.tate.2013.03.007

Sachdeva, A., \& Verma, R. (2015). Internet Gaming Addiction: A technological hazard. International Journal of High Risk Behaviors and Addiction, 4(4), 1-3. https://doi:10.5812/ijhrba.26359 
Shadzi, M., Salehi, A., \& Vardanjani, H. (2020). Problematic Internet use, mental health, and sleep quality among medical students: A path-analytic model. Indian Journal of Psychological Medicine, 42(2), 128-135. https://doi:10.4103/ijpsym.ijpsym_238_19

Shekarkhar, Z., \& Gibson, C. L. (2011). Gender, self-control, and offending behaviors among latino youth. Journal of Contemporary Criminal Justice, 27(1), 63-80. https:// doi:10.1177/1043986211402224

Spada, M. M. (2014). An overview of problematic Internet use. Addictive Behaviors, 39(1), 3-6. https://doi.org/10.1016/j. addbeh.2013.09.007

Su, W., Han, X., Jin, C., Yan, Y., \& Potenza, M. N. (2019). Are males more likely to be addicted to the internet than females? A metaanalysis involving 34 global jurisdictions. Computers in Human Behavior, 99, 86-100. https://doi.org/10.1016/j.chb.2019.04.021

Tangney, J. P., Baumeister, R. F., \& Boone, A. L. (2004). High SelfControl Predicts Good Adjustment, Less Pathology, Better Grades, and Interpersonal Success. Journal of personality, 72(2), 271-322.

Van Deursen, A. J. A. M., Bolle, C. L., Hegner, S. M., \& Kommers, P. A. M. (2015). Modeling habitual and addictive smartphone behavior: The role of smartphone usage types, emotional intelligence, social stress, self-regulation, age, and gender. Computers in Human Behavior, 45, 411-420. https://doi. org/10.1016/j.chb.2014.12.039

Wei, Z., Zheng, Z., Zhang, Y., Song, R., Zhu, J., Wan, G., \& Peng, Z. (2017). The relationship between Internet addiction and internalizing problems in overweight/obese adolescents: A moderated mediation model. North American Journal of Medicine and Science, 10(4), 139-147. https://doi:10.7156_ najms.2017.1004139

Yan, W., Li, Y., \& Sui, N. (2014). The relationship between recent stressful life events, personality traits, perceived family functioning and internet addiction among college students. Stress and Health, 30(1), 3-11. https://doi:10.1002/smi.2490

Yang, C. Y., Sato, T., Yamawaki, N., \& Miyata, M. (2013). Prevalence and risk factors of problematic Internet use: A crossnational comparison of Japanese and Chinese university 
IJMS 27(2), 77-96 (2020)

students. Transcultural Psychiatry, 50(2), 263-279. https:// doi:10.1177/1363461513488876

Zhang, M. W. B., Lim, R. B. C., Lee, C., \& Ho, R. C. M. (2018). Prevalence of Internet addiction in medical students: A metaanalysis. academic psychiatry, 42(1), 88-93. https://doi:10.1007/ s40596-017-0794-1 